\title{
Analysis of the two dimensional sheet debris flight equations: initial and final
}

\section{state}

Scarabino, A. and Giacopinelli, P.

Departamento Aeronáutica, Universidad Nacional de La Plata, Calle 116 e/ 47 y 48, 1900 La Plata, Argentina. scarabino@ing.unlp.edu.ar

\begin{abstract}
This work presents some analytical and numerical results of a dynamic analysis of the dimensionless 2-D sheet flight equations. Two empirical models for aerodynamic forces and moments are used and compared. Results show that the initial condition of rest is always unstable, and for long times three distinct flight regimes are possible, depending on the initial angle of attack, the Tachikawa number, Ta (in fact, the parameter chosen was its inverse, $\Omega$ ), and a mass ratio $\Phi$. The final orbits in the velocity space and their maximum kinetic energy are compared with a theoretical asymptotic state of the motion equations, and some design considerations are proposed.
\end{abstract}

Keywords: sheet debris, stability, aerodynamic forces.

\section{INTRODUCTION}

A considerable part of the damage produced in wind storms is not due simply to the wind loads on buildings and structures, but to the impact of windborne debris.

Holmes et al (2006) and Baker (2007) list some of the historical research in this topic, which is surprisingly sparse, despite its economic importance. The pioneer and fundamental work of Masao Tachikawa (Tachikawa 1983, Tachikawa 1988) has been recognized in the wind engineering community. One of the fundamental parameters in the dynamics of windborne debris flight, namely the non-dimensional ratio of aerodynamic forces to gravity forces, is 
today known as the Tachikawa number, Ta, after the proposal of Holmes, Baker and Tamura (2006), unanimously approved by the International Association of Wind Engineering in its General Assembly of year 2007.

As Wills et al (2002) point out, the cumulative damage inflicted by the debris, particularly on cladding elements, may lead to serious external damage or even to breaching of the building envelope. In their work they identify three generic debris types: compact, sheet and rod, a convenient classification accepted today by different researchers.

In the last years wind tunnel experiments have been carried out and debris velocities and trajectories have been measured (Wang and Letchford 2003, Holmes 2004, Lin et al 2006). Holmes et al (2006) and Baker (2007) have implemented numerical models for the equations of debris flight that reproduce acceptably some results of these and other wind tunnel experiments.

The sheet debris flight is particularly interesting due to the strong dependence of the aerodynamic forces on the sheet angle of attack. This turns the governing equation into a highly non-linear system, where the long-term evolution of the sheet flight can reach completely different states, depending on the initial conditions and a few relations of characteristic magnitudes. Baker (2006) performed a numerical research with an approximate model for aerodynamic forces on the sheet. Holmes et al (2006), on their side, used the empirical force coefficients measured by Flachsbart (1932) and reported by Hoerner (1965).

A problem similar in many aspects to that of sheet debris flight is the flutter, tumble and vortex induced autorotation of falling wings or plates. This could be considered a limit state of debris flight when the wind velocity is very small and was studied among others by Fremaux et al (1995), Mittal and Seshadri (2004) and Gallaway and Hankey (1985), who found in numerical simulations that free falling autorotating plates experienced considerably larger autorotation coefficients than those obtained at static angles of attack.

In the first part of this work the initial stability of the two-dimensional equations for sheet debris flight in uniform wind is studied analytically, proving that the system initially at rest is 
unstable for all angles of attack. In the second part, the final condition is investigated for different values of the initial angle, mass ratio and the inverse of $\mathrm{Ta}$. Three possible regimes are found, depending on the values of these parameters: positive rotation, negative rotation and back-and-forth oscillations. The simulations were carried out with the two models for aerodynamic forces adopted respectively by Baker (2007) and Holmes (2006), and the differences in the results are reported. The maximum kinetic energy in each long-term condition is compared with the analytical asymptotic solution of the equations, showing that these values can underestimate considerably the sheet potential impact energy.

\section{SHEET DEBRIS FLIGHT EQUATIONS}

The general two dimensional equations for flying debris are derived from Newton's second law, are (Baker, 2007):

$$
\begin{aligned}
& M \frac{d^{2} x}{d t^{2}}=M \frac{d u}{d t}=\frac{A \rho}{2}\left(C_{D} \cos \alpha-\left(C_{L}+C_{L A}\right) \sin \alpha\right)\left(\left(U_{w}-u\right)^{2}+\left(V_{w}-v\right)^{2}\right) \\
& M \frac{d^{2} y}{d t^{2}}=M \frac{d v}{d t}=\frac{A \rho}{2}\left(\left(C_{L}+C_{L A}\right) \cos \alpha+C_{D} \sin \alpha\right)\left(\left(U_{w}-u\right)^{2}+\left(V_{w}-v\right)^{2}\right)-M g \\
& I \frac{d^{2} \theta}{d t^{2}}=I \frac{d \omega}{d t}=\left(\frac{\left(C_{M}+C_{M A}\right) A l \rho}{2}\right)\left(\left(U_{w}-u\right)^{2}+\left(V_{w}-v\right)^{2}\right)
\end{aligned}
$$

Here $x$ and $y$ are the sheet CG position, $\theta$ its inclination with respect to the horizontal axis, $u$ and $v$ the sheet horizontal and vertical velocity components, $\omega$ the sheet angular velocity, $M$ is the sheet mass, $A$ its area, $l$ its length in the plane of motion, $I$ its moment of inertia, $\rho$ the air density, $U_{w}$ and $V_{w}$ the horizontal and vertical components of the wind velocity, and $\alpha$ the angle between the wind and the sheet velocity.

$C_{D}, C_{L}$ and $C_{M}$ are the aerodynamic drag, lift and pitching moment coefficients, that depend primarily on the angle of attack $\beta$ (angle between the relative wind and the sheet axis), and 
$C_{L A}$ and $C_{M A}$ are the autorotation lift and moment coefficients, function of the angular velocity $\omega$.

Positive values of $u, v$ and $\theta$ are shown in figure 1 :

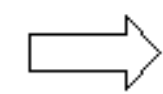

$\mathrm{U}_{\mathrm{W}}$

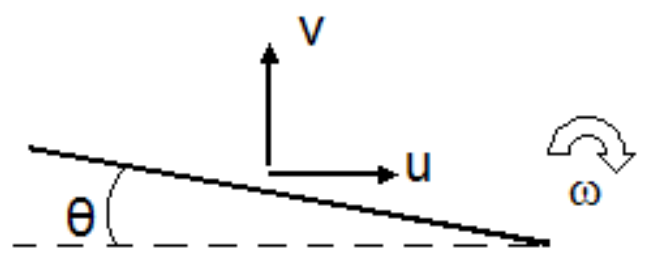

Figure 1: positive values of $u, v$ and $\theta$

The angle $\alpha$ between the relative wind velocity vector and the horizontal can be expressed in terms of $U_{w}, V_{w}, u$ and $v$ and the equations can be written for steady uniform horizontal wind in non dimensional form, following Baker (2007) as:

$\frac{d^{2} \bar{x}}{d \bar{t}^{2}}=\frac{d \bar{u}}{d \bar{t}}=\left(C_{D}(1-\bar{u})+\left(C_{L}+C_{L A}\right) \bar{v}\right)\left((1-\bar{u})^{2}+\bar{v}^{2}\right)^{\frac{1}{2}}$

$\frac{d^{2} \bar{x}}{d \bar{t}^{2}}=\frac{d \bar{v}}{d \bar{t}}=\left(\left(C_{L}+C_{L A}\right)(1-\bar{u})-C_{D} \bar{v}\right)\left((1-\bar{u})^{2}+\bar{v}^{2}\right)^{\frac{1}{2}}-\Omega$

$\frac{d^{2} \bar{\theta}}{d \bar{t}^{-2}}=\frac{d \bar{\omega}}{d \bar{t}}=\Delta\left(C_{M}+C_{M A}\right)\left((1-\bar{u})^{2}+\bar{v}^{2}\right)^{\frac{1}{2}}$

with

$\bar{x}=\frac{x}{l} \Phi ; \quad \bar{y}=\frac{y}{l} \Phi ; \quad \bar{u}=\frac{u}{U_{w}} ; \quad \bar{v}=\frac{v}{U_{w}} ; \quad \bar{t}=\frac{t U_{w}}{l} \Phi$

$\bar{\theta}=\theta \Phi ; \quad \bar{\omega}=\frac{\omega l}{U_{w}} ; \quad \Delta=\frac{M l^{2}}{I} ; \quad \Omega=\frac{M g}{0.5 \rho A U_{w}^{2}}$ 
The parameter $\Omega$ is equal to the inverse of Ta, the Tachikawa number. The parameter $\Phi$ is a non-dimensional mass relation:

$\Phi=\frac{0.5 \rho A l}{M}$

An alternative formulation, not used in this work, was implemented by Tachikawa (1983).

\subsection{Aerodynamic coefficients adopted by Holmes et al (2006)}

Two different sets of aerodynamic coefficients were chosen for this work. This is a somewhat arbitrary choice, since different authors use other models. There is at present no consensus on a simple non-stationary aerodynamic model to be employed for rotating or pitching flat plates at arbitrary angles of attack.

The equations for aerodynamic forces adopted in Holmes et al (2006) is based on the normal forces on a square plate compiled by Hoerner (1965) from a report by Flaschbart (1932)

$$
\begin{array}{ll}
C_{N}=1.7 \frac{\beta}{40} & \text { for } \beta<40^{\circ} \\
C_{N}=1.15 & \text { for } 40^{\circ} \leq \beta<140^{\circ} \\
C_{N}=1.7 \frac{(180-\beta)}{40} & \text { for } 140^{\circ} \leq \beta<180^{\circ}
\end{array}
$$

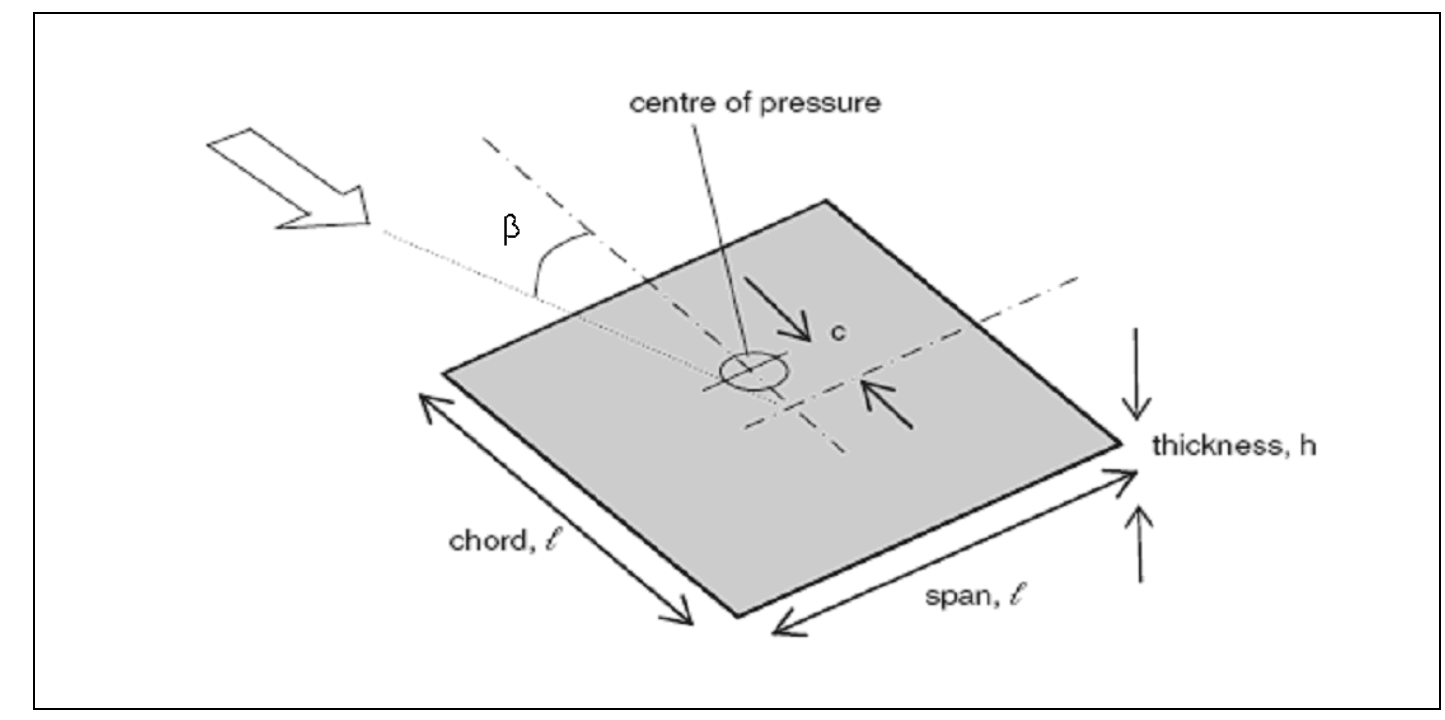

Figure 2: Scheme of a sheet object, from Holmes et al (2006). 
Here $\beta$ is the direction of the wind velocity relative to the axis of the object and is given by

$$
\beta=\theta+\cos ^{-1}\left(\frac{(1-\bar{u})}{\sqrt{(1-\bar{u})^{2}+\bar{v}^{2}}}\right)
$$

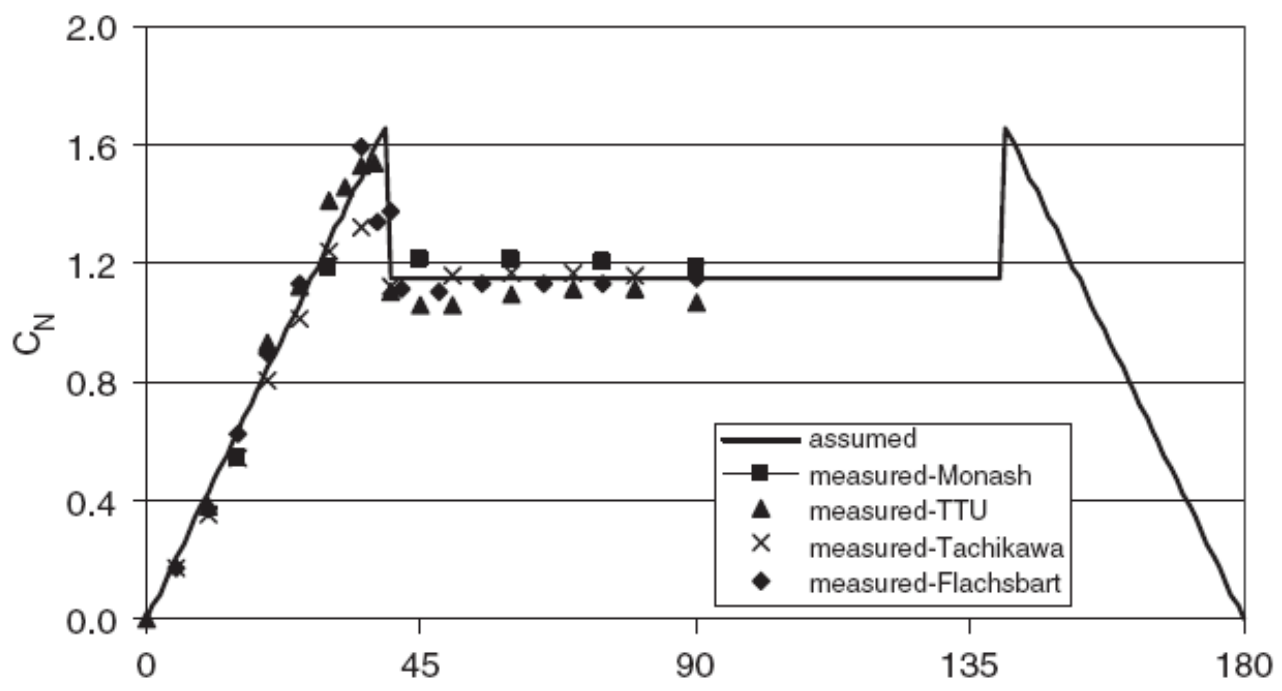

Figure 3: Normal force coefficient on a plate, from Holmes et al. (2006)

From the normal force coefficients the drag and lift coefficient are derived:

$$
\begin{aligned}
& C_{D}=0.1+C_{N} \sin (\beta) \\
& C_{L}=C_{N} \cos (\beta)
\end{aligned}
$$

The constant value 0.1 in the drag coefficient is added to allow for the skin friction component in the non-stationary plate motion. For the quasi-static moments, the pressure center position "c" must be computed. This value can be approximated as (Holmes et al 2006):
$(c / l)=0.3-0.22(\beta / 38)$
for $0^{\circ} \leq \beta \leq 38^{\circ}$
$(c / l)=0.08 \cos [2(\beta-38)]$
for $38^{\circ}<\beta<82.5^{\circ}$
$(c / l)=0.0$
for $82.5^{\circ} \leq \beta<97.5^{\circ}$
$(c / l)=-0.08 \cos [2(142-\beta)]$
for $97.5^{\circ}<\beta \leq 142^{\circ}$
$(c / l)=-0.3+0.22[(180-\beta) / 38]$ for $142^{\circ}<\beta \leq 180^{\circ}$ 
And the moment coefficient $\mathrm{C}_{M}$ is

$$
C_{M}=C_{N}\left(\frac{c}{l}\right)
$$

Autorotation lift coefficients (Magnus effect) are:

$$
\begin{aligned}
& C_{L A}=0.42\left(2.5 \omega / \omega_{m}\right) \quad \text { for } \quad\left|\omega / \omega_{m}\right|<0.2 \\
& C_{L A}=\operatorname{sgn}(\omega)^{*} 0.42\left(0.375+0.625\left|\omega / \omega_{m}\right|\right) \quad \text { for } \quad\left|\omega / \omega_{m}\right| \geq 0.2
\end{aligned}
$$

With maximum and minimum (negative) values of $\omega$ equal to $\omega_{\mathrm{m}}= \pm 0.64 U / l$

These equations will be referred to as "Holmes' model".

\subsection{Baker's approximated aerodynamic coefficients}

The quasi-steady force and moment coefficients are approximated as (Baker 2007):

$$
\begin{aligned}
& C_{D}=0.75\left(1+0.65 \sin \left(2 \beta-\frac{\pi}{2}\right)\right) \\
& C_{L}=1.2 \sin (2 \beta) \\
& C_{M}=0.2 \cos (\beta)\left(C_{D} \sin (\beta)+C_{L} \cos (\beta)\right)
\end{aligned}
$$

These lift, drag and moment coefficient variation, are taken as a smooth analytical approximation, that give normal forces and centre of pressure location similar to those of Holmes model. In Figure 4 lift, drag, and moment coefficients are shown for both models. 

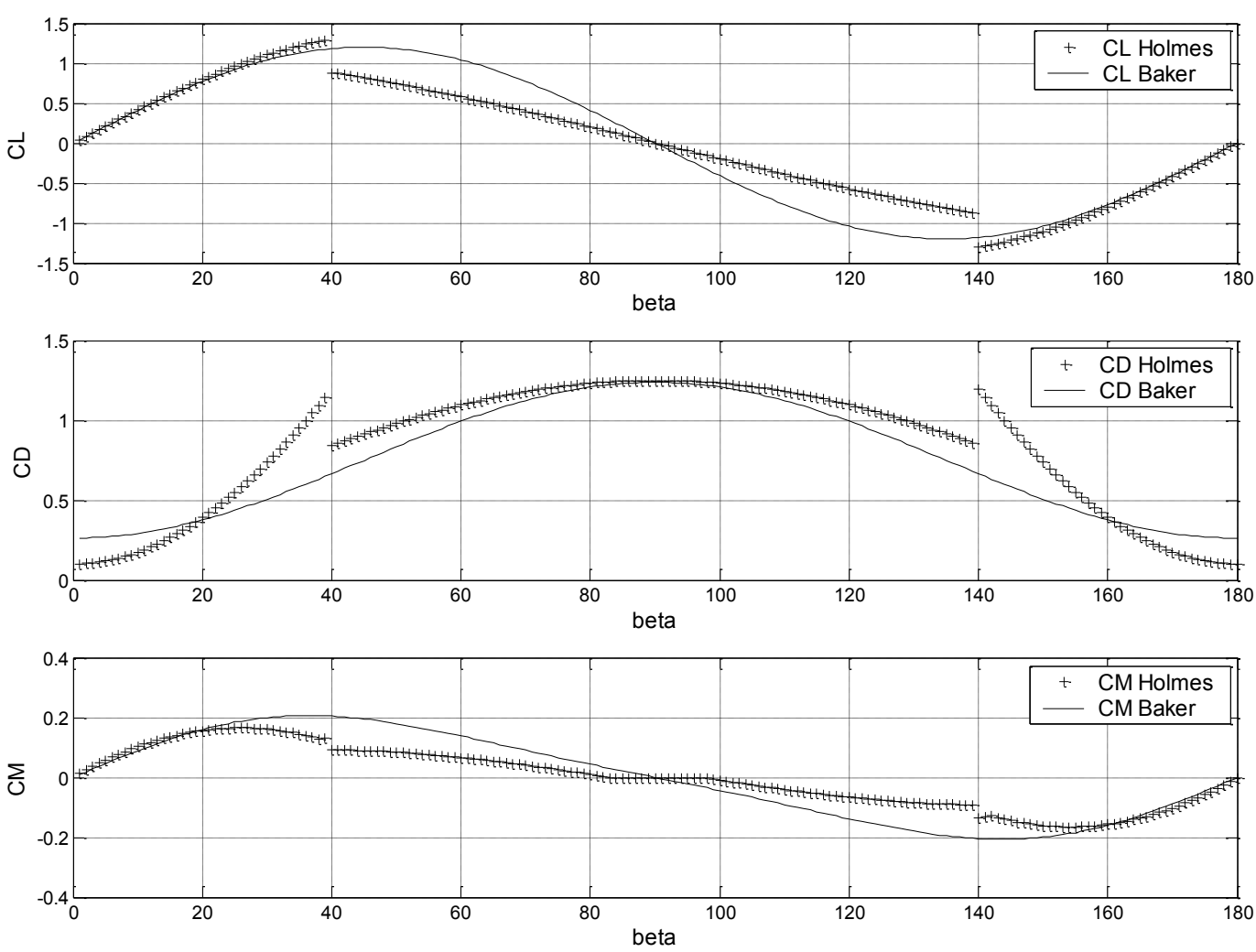

Figure 4: Baker's and Holmes' models for lift, drag and pitching moment coefficient for sheet objects

The following forms are adopted for the autorotation coefficients:

$C_{L A}=k_{L A}\left(\omega / \omega_{m}\right)$
$C_{M A}=k_{M A}\left(1-\left|\omega / \omega_{m}\right|\right)\left(\omega / \omega_{m}\right)$

Where $\varpi_{m}$ is the maximum numerical value of $\varpi$ and is taken to be 0.64 . The constants $\mathrm{k}_{\mathrm{LA}}$ for autorotation lift and $\mathrm{k}_{\mathrm{MA}}$ for the autorotation pitching moment are taken to have the values of 0.4 and 0.12 , respectively.

These equations will be referred as Baker's model. Earlier results published by Lugt (1983) and Iversen (1979) state the importance of $\bar{\omega}$ as a controlling parameter for autorotation motions. Lugt also states that for autorotation, the flow patterns are essentially independent of the Reynolds number and are even similar for the laminar and turbulent cases. 


\subsection{Asymptotic solutions}

It is possible to derive asymptotic solutions to eqs. (2) for large times, by assuming that the sheet is rotating at its maximum rate and thus $C_{L A}=k_{L A}, C_{M A}=0$ and considering that the quasi-steady force and moment coefficients take on their average values:

$$
\begin{aligned}
& C_{D}=\overline{C_{D}} \\
& C_{L}=C_{M}=0
\end{aligned}
$$

These assumptions give the following results, reported in Baker 2007:

$$
\begin{aligned}
& \bar{u}=1 \pm\left(\frac{\Omega}{\overline{C_{D}}}\right)^{0.5}\left(\frac{\overline{C_{D}}}{k_{L A}}\right)^{0.5}\left(1+\frac{{\overline{C_{D}}}^{2}}{{k_{L A}}^{2}}\right)^{-0.75} \\
& \bar{v}=-\left(\frac{\Omega}{\overline{C_{D}}}\right)^{0.5}\left(\overline{\frac{C_{D}}{k_{L A}}}\right)^{1.5}\left(1+\frac{{\overline{C_{D}}}^{2}}{{k_{L A}}^{2}}\right)^{-0.75} \\
& \bar{\omega}=\overline{\omega_{M}}
\end{aligned}
$$

An alternative way of writing this asymptotic solution is:

$$
\begin{aligned}
& \bar{u}=1 \pm\left(\frac{\Omega}{\overline{C_{D}}}\right)^{0.5}\left(\frac{k_{L A}}{\overline{C_{D}}}\right)^{0.5}\left[1+\left(\frac{k_{L A}}{\overline{C_{D}}}\right)^{2}\right]^{-0.75} \\
& \bar{v}=-\left(\frac{\Omega}{\overline{C_{D}}}\right)^{0.5}\left[1+\left(\frac{k_{L A}}{\overline{C_{D}}}\right)^{2}\right]^{-0.75} \\
& \bar{\omega}=\overline{\omega_{M}}
\end{aligned}
$$


These equations show that with no rotation $\left(\mathrm{k}_{\mathrm{LA}}=0\right)$, the asymptotic velocities are $\bar{u}=1$ (the sheet horizontal velocity is equal to the wind velocity) and $\bar{v}=-\left(\frac{\Omega}{\overline{C_{D}}}\right)^{0.5}$ (the weight is balanced by the aerodynamic drag), the same result as for compact debris (Baker 2007). The final dimensionless kinetic energy in this case can be computed as

$$
\bar{E}=\frac{E}{M U^{2}}=\frac{\bar{u}^{2}+\bar{v}^{2}+\bar{\omega}^{2} / \Delta}{2}
$$

which gives for the asymptotic values

$$
\bar{E}=\frac{1}{2}\left(1+\left(\frac{\Omega}{\overline{C_{D}}}\right)\left(\frac{\overline{C_{D}}}{k_{L A}}\right)\left(1+\frac{{\overline{C_{D}}}^{2}}{{k_{L A}}^{2}}\right)^{-0.5} \pm 2\left(\frac{\Omega}{\overline{C_{D}}}\right)^{0.5}\left(\frac{\overline{C_{D}}}{k_{L A}}\right)^{0.5}\left(1+\frac{{\overline{C_{D}}}^{2}}{{k_{L A}}^{2}}\right)^{-0.75}+\frac{{\overline{\omega_{M}}}^{2}}{\Delta}\right)
$$

The positive sign in the last term corresponds to a final state of negative rotation, and a negative sign correspond to positive rotation.

These results are derived from the assumption that the flying object reaches final constant velocities $\bar{u}, \bar{v}$ and $\bar{\omega}$. Baker's simulations for typical values of the parameters $\Delta=12$ (rectangular plates) and $\Omega=1.02$ (small sheet debris) and 0.163 (large sheet debris), show that for long term simulations the horizontal and vertical velocities oscillate around their mean values in periodical orbits. In this work the final kinetic energy predicted by eq. (18) is compared with the instantaneous values in the final state of the debris flight, in order to perform safer estimates of debris impact. 


\section{METHODOLOGY}

Equations (2) can be written as:

$\left[\begin{array}{l}\frac{d \bar{u}}{d t} \\ \frac{d \bar{v}}{d t} \\ \frac{d \bar{\omega}}{d t}\end{array}\right]=\left[\begin{array}{c}F_{u}(\bar{u}, \bar{v}, \bar{\omega}) \\ F_{v}(\bar{u}, \bar{v}, \bar{\omega}) \\ F_{\omega}(\bar{u}, \bar{v}, \bar{\omega})\end{array}\right]$

From these, the time evolution of $\bar{u}, \bar{v}$ and $\bar{\omega}$ is computed explicitly for discrete time increments $\Delta \bar{t}$ as:

$\left[\begin{array}{c}\bar{u} \\ \bar{v} \\ \bar{\omega}\end{array}\right]^{(t+\Delta t)}=\left[\begin{array}{c}\bar{u} \\ \bar{v} \\ \bar{\omega}\end{array}\right]^{(t)}+\Delta \bar{t}\left[\begin{array}{c}F_{u}(\bar{u}, \bar{v}, \bar{\omega}) \\ F_{v}(\bar{u}, \bar{v}, \bar{\omega}) \\ F_{\omega}(\bar{u}, \bar{v}, \bar{\omega})\end{array}\right]^{(t)}$

The dimensionless time interval chosen for this work was 0.005 . With this value, the velocities evolution and trajectories were identical to those reported by Holmes et al (2006) and Baker (2007), with his approximated model, and reproduced acceptably well Tachikawa's experimental results, as shown in the mentioned papers. The simulations were checked against results of an adaptive time step numerical method (Matlab ode45 function) in order to prevent possible numerical instabilities due to the use of fixed time steps in non linear problems, and the chosen time step of 0.005 showed to be appropriate.

In order to compute and analyze the final orbits, the simulation runs were extended up to $\bar{t}=200$ and the system evolution was study between $\bar{t}=100$ and 200 , when the sheet velocities had already reached a periodical or quasi-periodical variation.

In order to study the system stability we analysed first eq. (19). No fix points (equilibrium points constants in time) were found for the system. 
Equations (19) were then linearised for small perturbations $\overline{u^{\prime}}, \overline{v^{\prime}}, \overline{\omega^{\prime}}$ around the point of analysis and the system behaviour was studied considering the eigenvalues of matrix $A$. (Elsgoltz, 1977)

$$
\left[\begin{array}{l}
\frac{d \overline{u^{\prime}}}{d \bar{t}} \\
\frac{d \overline{v^{\prime}}}{d \bar{t}} \\
\frac{d \overline{\omega^{\prime}}}{d \bar{t}}
\end{array}\right]=A(\bar{u}, \bar{v}, \bar{\omega})\left[\begin{array}{c}
\overline{u^{\prime}} \\
\overline{v^{\prime}} \\
\overline{\omega^{\prime}}
\end{array}\right] \quad \text { with } \quad A=\left[\begin{array}{lll}
\frac{d F_{u}}{d \bar{u}} & \frac{d F_{u}}{d \bar{v}} & \frac{d F_{u}}{d \bar{\omega}} \\
\frac{d F_{v}}{d \bar{u}} & \frac{d F_{v}}{d \bar{v}} & \frac{d F_{v}}{d \bar{\omega}} \\
\frac{d F_{\omega}}{d \bar{u}} & \frac{d F_{\omega}}{d \bar{v}} & \frac{d F_{\omega}}{d \bar{\omega}}
\end{array}\right]
$$

\section{RESULTS}

\subsection{Initial stability analysis}

For $\overline{(u}, \bar{v}, \bar{\omega})=(0,0,0)$ the object is at rest and the determinant parameter for the acting forces is the initial angle of incidence of the relative wind. The relative non dimensional velocity modulus $\left|\bar{V}_{r e l}\right|=\sqrt{(1-\bar{u})^{2}+\bar{v}^{2}}$ is 1 . In consequence, we have from eq. (21):

$$
A^{0}=\left[\begin{array}{ccc}
-C_{D}{ }^{0} & C_{L}{ }^{0} & 0 \\
-C_{L}{ }^{0} & -C_{D}{ }^{0} & \frac{k_{L A}}{\overline{\omega_{m}}} \\
-2 \Delta C_{M}{ }^{0} & 0 & \Delta \frac{k_{M A}}{\overline{\omega_{m}}}
\end{array}\right]
$$

Superindex 0 indicates the initial values, which depend on the initial angle $\theta^{0}$ in this case, and on $\beta^{0}$ in case of an initial condition different from rest. The characteristic polynomial of matrix $A^{0}$ is

$$
P(\lambda)=\lambda^{3}+\left(2 C^{0}{ }_{D}-\Delta \frac{k_{M A}}{\omega_{m}}\right) \lambda^{2}+\left(C^{0}{ }_{D}-2 C^{0}{ }_{D} \Delta \frac{k_{M A}}{\omega_{m}}\right) \lambda-\left[\Delta \frac{k_{M A}}{\omega_{m}}\left(C^{0}{ }_{D}^{2}+C^{0}{ }_{L}^{2}\right)+2 \Delta C^{0}{ }_{M} C^{0}{ }_{L} \frac{k_{L A}}{\omega_{m}}\right]
$$


The analysis was performed with the characteristic values:

$\omega_{m}=0.64$

$\Delta=12 ; \quad$ (rectangular plates)

$\mathrm{k}_{\mathrm{LA}}=0.4$

$\mathrm{k}_{\mathrm{MA}}=0.12$

Equation (23) is independent of the parameters $\Omega$ and $\Phi$. For all values of the $\theta^{\circ}$ between $0^{\circ}$ and $180^{\circ}$ and the characteristic parameters (24) and using both Holmes' and Baker's aerodynamic forces models, at least one of the roots of eq. (23) is positive, between 2.19 and 2.52, as shown in Table I. Thus the system is always unstable and any perturbation will be amplified, starting the sheet flight. The second and third eigenvalues of $A$ are either negative or complex with negative real part.

Table I: Eigenvalues of the stability matrix at rest

\begin{tabular}{|c|c|c|c|c|c|c|c|c|c|}
\hline$\beta_{0}$ & Model & $\lambda_{1}$ & $\lambda_{2}$ & $\lambda_{3}$ & $\beta_{0}$ & Model & $\lambda_{1}$ & $\lambda_{2}$ & $\lambda_{3}$ \\
\hline 0 & $\begin{array}{l}\mathrm{B} \\
\mathrm{H}\end{array}$ & $\begin{array}{l}2.25 \\
2.25\end{array}$ & $\begin{array}{l}-0.26 \\
-0.10\end{array}$ & $\begin{array}{l}-0.26 \\
-0.10\end{array}$ & 90 & $\begin{array}{l}B \\
H\end{array}$ & $\begin{array}{l}2.48 \\
2.25\end{array}$ & $\begin{array}{c}-1.3545+ \\
0.9257 i \\
-1,25\end{array}$ & $\begin{array}{c}-1.3545- \\
0.9257 i \\
-1,25\end{array}$ \\
\hline 10 & $\begin{array}{l}\mathrm{B} \\
\mathrm{H}\end{array}$ & $\begin{array}{l}2.24 \\
2.21\end{array}$ & $\begin{array}{l}-0.44 \\
-0.48\end{array}$ & $\begin{array}{c}-0.13 \\
0.17\end{array}$ & 100 & $\begin{array}{l}\mathrm{B} \\
\mathrm{H}\end{array}$ & $\begin{array}{l}2.52 \\
2.24\end{array}$ & $\begin{array}{c}-1.3430+ \\
0.9936 \mathrm{i} \\
-1.37\end{array}$ & $\begin{array}{c}-1.3430- \\
0.9936 i \\
-1.09\end{array}$ \\
\hline 20 & $\begin{array}{l}\mathrm{B} \\
\mathrm{H}\end{array}$ & $\begin{array}{l}2.22 \\
2.18\end{array}$ & $\begin{array}{l}-0.65 \\
-0.77\end{array}$ & $\begin{array}{r}-0.07 \\
0.06\end{array}$ & 110 & $\begin{array}{l}B \\
H\end{array}$ & $\begin{array}{l}2.52 \\
2.24\end{array}$ & $\begin{array}{c}-1.2602+ \\
0.9891 \mathrm{i} \\
-1.34\end{array}$ & $\begin{array}{c}-1.2602- \\
0.9891 \mathrm{i} \\
-1.01\end{array}$ \\
\hline 30 & $\begin{array}{l}B \\
H\end{array}$ & $\begin{array}{l}2.20 \\
2.26\end{array}$ & $\begin{array}{c}-0.86 \\
-0.7417+ \\
0.1590 \mathrm{i}\end{array}$ & $\begin{array}{c}-0.10 \\
-0.7417- \\
0.1590 \mathrm{i}\end{array}$ & 120 & $\begin{array}{l}\mathrm{B} \\
\mathrm{H}\end{array}$ & $\begin{array}{l}2.49 \\
2.25\end{array}$ & $\begin{array}{c}-1.1155+ \\
0.9135 i \\
-1.17\end{array}$ & $\begin{array}{c}-1.1155- \\
0.9135 i \\
-1.02\end{array}$ \\
\hline 40 & $\begin{array}{l}\mathrm{B} \\
\mathrm{H}\end{array}$ & $\begin{array}{l}2.19 \\
2.30\end{array}$ & $\begin{array}{c}-1.04 \\
-0.8662+ \\
0.4111 \mathrm{i} \\
\end{array}$ & $\begin{array}{c}-0.23 \\
-0.8662- \\
0.4111 \mathrm{i}\end{array}$ & 130 & $\begin{array}{l}\text { B } \\
\mathrm{H}\end{array}$ & $\begin{array}{l}2.44 \\
2.27\end{array}$ & $\begin{array}{c}-0.9276+ \\
0.7740 \mathrm{i} \\
-0.9910+ \\
0.2551 \mathrm{i}\end{array}$ & $\begin{array}{c}-0.9276- \\
0.7740 \mathrm{i} \\
-0.9910- \\
0.2551 \mathrm{i}\end{array}$ \\
\hline 50 & $\begin{array}{l}B \\
H\end{array}$ & $\begin{array}{l}2.22 \\
2.28\end{array}$ & $\begin{array}{c}-1.12 \\
-0.9950+ \\
0.3018 \mathrm{i}\end{array}$ & $\begin{array}{c}-0.52 \\
-0.9950- \\
0.3018 \mathrm{i}\end{array}$ & 140 & $\begin{array}{l}\text { B } \\
\mathrm{H}\end{array}$ & $\begin{array}{l}2.36 \\
2.36\end{array}$ & $\begin{array}{c}-0.7225+ \\
0.5857 \mathrm{i} \\
-1.2478+ \\
0.6228 \mathrm{i}\end{array}$ & $\begin{array}{c}-0.7225- \\
0.5857 \mathrm{i} \\
-1.2478- \\
0.6228 \mathrm{i}\end{array}$ \\
\hline 60 & $\begin{array}{l}B \\
H\end{array}$ & $\begin{array}{l}2.28 \\
2.27\end{array}$ & $\begin{array}{c}-1.0068+ \\
0.2915 \mathrm{i} \\
-1.1036+ \\
0.2268 \mathrm{i} \\
\end{array}$ & $\begin{array}{c}-1.0068- \\
0.2915 \mathrm{i} \\
-1.1036- \\
0.2268 \mathrm{i}\end{array}$ & 150 & $\begin{array}{l}\text { B } \\
\mathrm{H}\end{array}$ & $\begin{array}{l}2.30 \\
2.40\end{array}$ & $\begin{array}{c}-0.5313+ \\
0.3741 \mathrm{i} \\
-0.8149+ \\
0.6930 \mathrm{i} \\
\end{array}$ & $\begin{array}{c}0.5313- \\
0.3741 \mathrm{i} \\
-0.8149- \\
0.6930 \mathrm{i} \\
\end{array}$ \\
\hline
\end{tabular}




\begin{tabular}{|c|c|c|c|c|} 
& $\mathrm{B}$ & 2.35 & $\begin{array}{c}-1.1729+ \\
0.5841 \mathrm{i}\end{array}$ & $\begin{array}{c}-1.1729- \\
0.5841 \mathrm{i} \\
70\end{array}$ \\
& $\mathrm{H}$ & 2.26 & $\begin{array}{c}-1.1853+ \\
0.1789 \mathrm{i}\end{array}$ & $\begin{array}{c}-1.1853- \\
0.1789 \mathrm{i}\end{array}$ \\
\hline & $\mathrm{B}$ & 2.42 & $\begin{array}{c}-1.2947+ \\
0.7883 \mathrm{i}\end{array}$ & $\begin{array}{c}-1.2947- \\
0.7883 \mathrm{i} \\
80\end{array}$ \\
& $\mathrm{H}$ & 2.26 & $\begin{array}{c}-1.2350+ \\
0.1321 \mathrm{i}\end{array}$ & $\begin{array}{c}-1.2350- \\
0.1321 \mathrm{i}\end{array}$ \\
\hline
\end{tabular}

\begin{tabular}{|c|c|c|c|c|}
\hline 160 & $\mathrm{H}$ & $\begin{array}{l}2.26 \\
2.39\end{array}$ & $\begin{array}{c}-0.3824+ \\
0.1760 \mathrm{i} \\
-0.4605+ \\
0.6189 \mathrm{i}\end{array}$ & $\begin{array}{c}-0.3824- \\
0.1760 \mathrm{i} \\
-0.4605- \\
0.6189 \mathrm{i}\end{array}$ \\
\hline \multirow{2}{*}{170} & B & 2.25 & $\begin{array}{c}-0.2921+ \\
0.0318 \mathrm{i}\end{array}$ & $\begin{array}{c}-0.2921- \\
0.0318 i\end{array}$ \\
\hline & $\mathrm{H}$ & & $\begin{array}{c}-0.2039+ \\
0.3857 i\end{array}$ & $\begin{array}{c}-0.2039- \\
0.3857 \mathrm{i}\end{array}$ \\
\hline
\end{tabular}

\subsection{Final state}

Numerical simulations were carried out with the different aerodynamic force models. In all cases, after initial oscillations that depend on the value of $\theta^{0}$ or $\beta^{0}$, the velocities reach periodical or quasi-periodical oscillations for large times, unlike the stationary final state assumed in equations (15) and (16). Three qualitatively different types of final motions or final orbits in the $\overline{(u}, \bar{v}, \bar{\omega})$ space can be identified, that depends on the parameters $\Phi, \Omega$ and $\beta^{0}$, but also on the choice of the aerodynamic model employed.

\subsubsection{Large debris, positive final rotation}

Figures 5 and 6 show the evolution of the system with $\left(\Omega=0.163, \Phi=0.05, \beta^{0}=15^{\circ}\right)$. These values correspond, for example, to a wooden board (density $800 \mathrm{~kg} / \mathrm{m}^{3}$ ) of $0.33 \mathrm{~m} \times 3 \mathrm{mx}$ $0.005 \mathrm{~m}$. at a wind speed of $20 \mathrm{~m} / \mathrm{s}$. In this case, the plate starts and continues its flight with positive angular velocity, reaching its final quasi-periodical velocities after a non-dimensional time $\bar{t}=5$. In this time, corresponding to $1.7 \mathrm{~s}$, the plate has travelled a distance of $18.8 \mathrm{~m}$ downwind and has fallen $3.3 \mathrm{~m}$. Figure $5 \mathrm{c}$ ) shows the projection of its orbit, computed with Holmes' model, in the $\bar{u}-\bar{v}$ plane. Baker's model produces a similar evolution, but the final state is slightly different, as shown in figure 6c). 
a) Baker's model

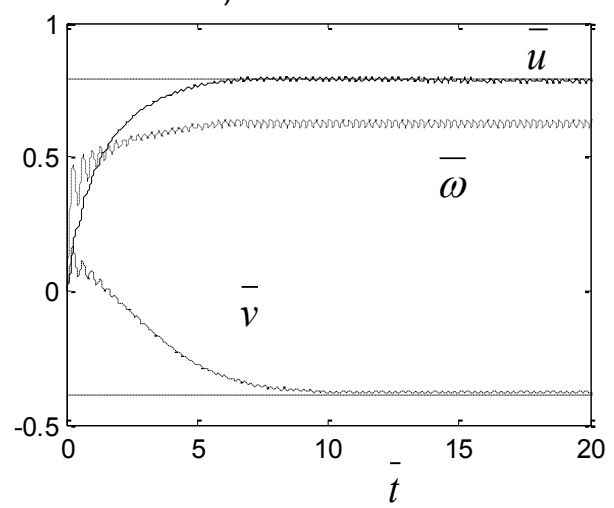

b) Holmes' model

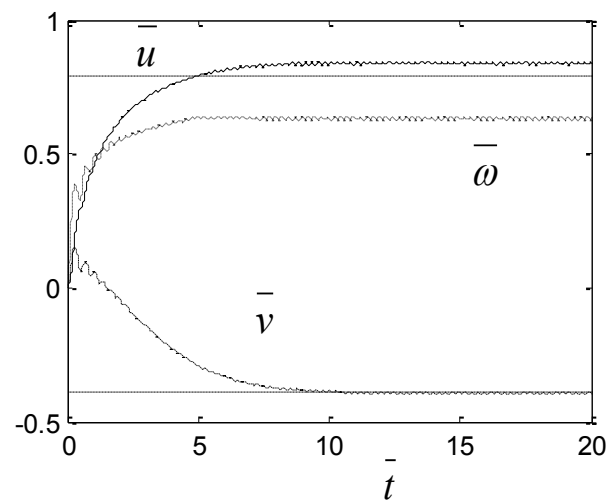

c) Orbit, Holmes

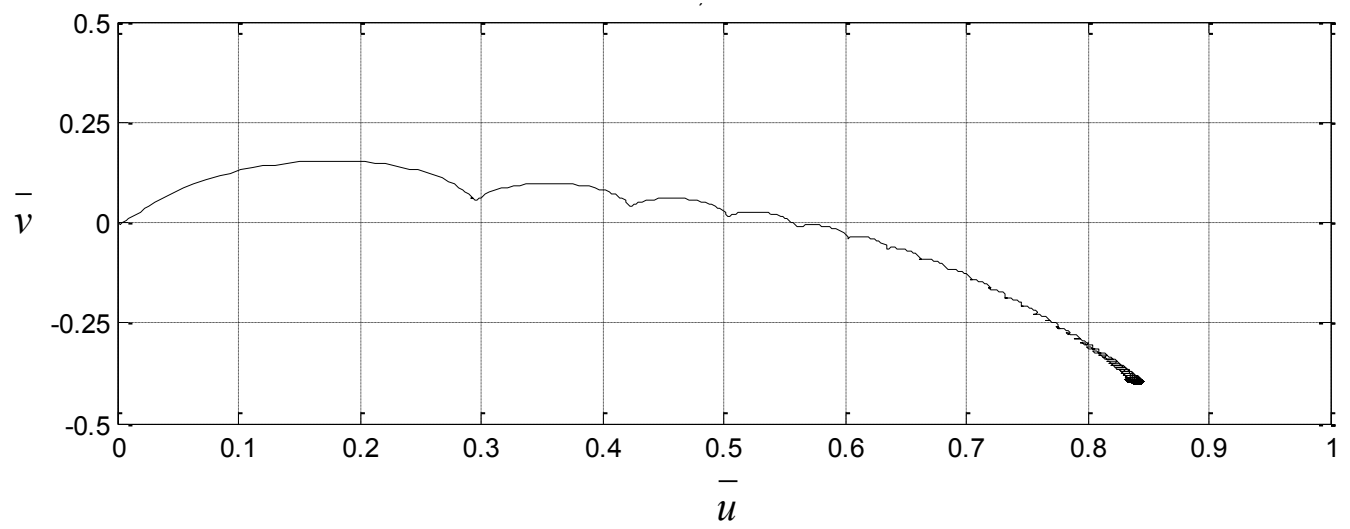

Figure 5: Large debris, positive final rotation. a) $\bar{u}, \bar{v}$ and $\bar{\omega}$ evolution, Baker's model, b) $\bar{u}, \bar{v}$ and $\bar{\omega}$ evolution, Holmes' model . Dashed lines: asymptotic values of $\bar{u}$ and $\bar{v}$ from eq. (15) c) Projection of the system orbit in the $\bar{u}-\bar{v}$ plane

The apparent thickness of the final orbit based on Holmes' coefficients is due to the fact that its trajectory is bounded but not strictly periodical, presenting the aspect of a chaotic attractor. The "correlation dimension" (Grassberger and Procaccia - 1983) of each final trajectory was computed, being 1 in all cases.

Unlike the limit stationary state assumed in equations (16), the system reaches a final orbit, which is periodical when using Baker's model and quasi-periodical with Holmes' model. In these orbits, the sheet kinetic energy fluctuates around a mean value, close to the theoretical limit of eq. (18) in Baker's approximation, but about $15 \%$ higher when using Holmes' coefficients derived from Hoerner's reports. 
The results of both models show that in this case the positive rotation slows down the sheet fall up to $40 \%$ approx. of the wind velocity, and the final mean horizontal velocity is lower than $85 \%$ of the wind velocity.

a) Kinetic energy, Baker

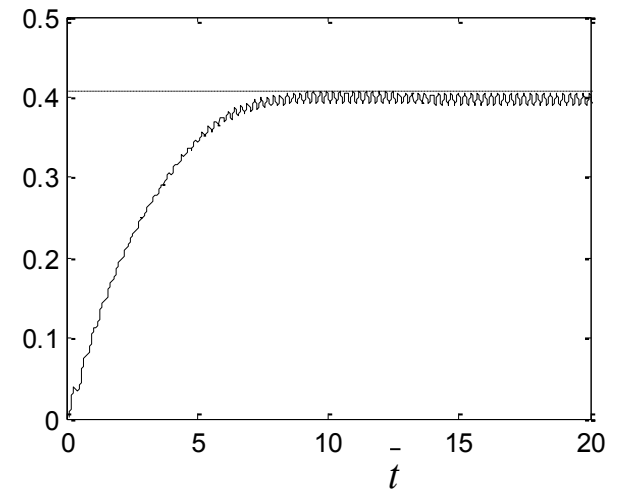

b) Kinetic energy, Holmes

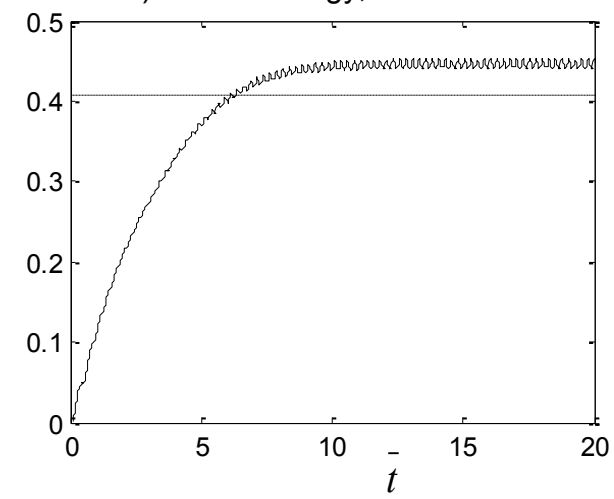

$\bar{u}-\bar{v}$ plane

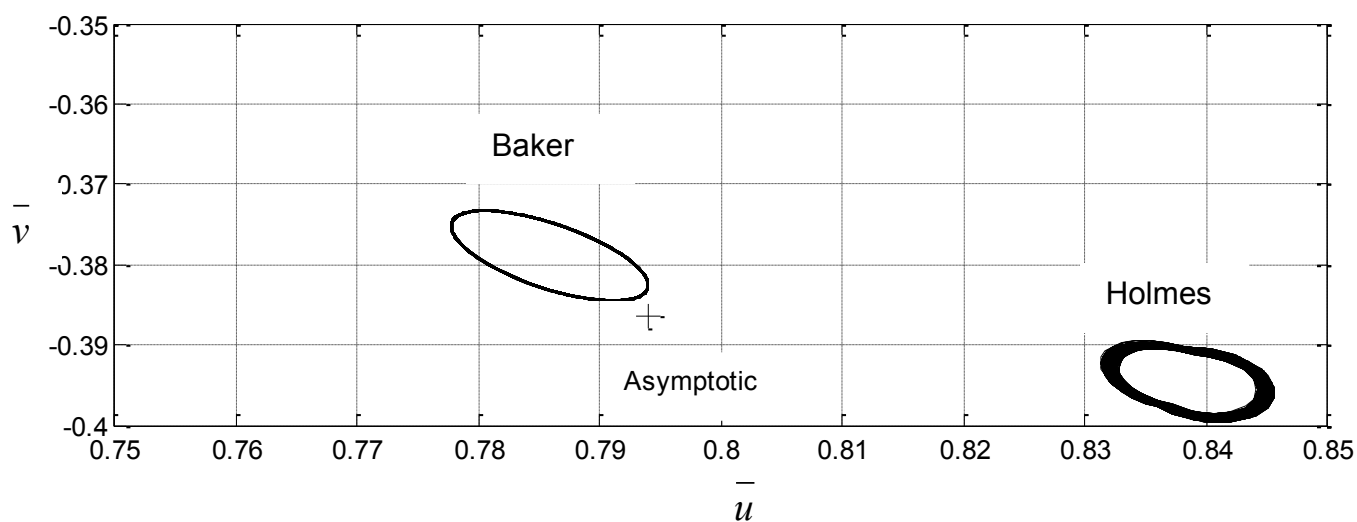

Figure 6: a) Kinetic energy evolution. Dashed: asymptotic value after eq. (18) b) Final orbits in $\bar{u}-\bar{v}$ space. The cross indicates the asymptotic final state.

\subsubsection{Large debris, negative final rotation.}

Figures 7 and 8 show the evolution of the system with $\Omega=0.163, \Phi=0.05, \beta^{0}=60^{\circ}$. For this large initial angle $\beta^{0}$, the sheet reaches a final state of negative angular velocity. The forces and moments induced by this rotation increase the horizontal velocity above that of the wind and make the modulus of the final negative vertical velocity larger than in the case of positive rotation. At a non-dimensional time of 7 , a real time of $2.3 \mathrm{~s}$, the plate has travelled $37.8 \mathrm{~m}$ and fallen $17 \mathrm{~m}$. 
a) Baker's model

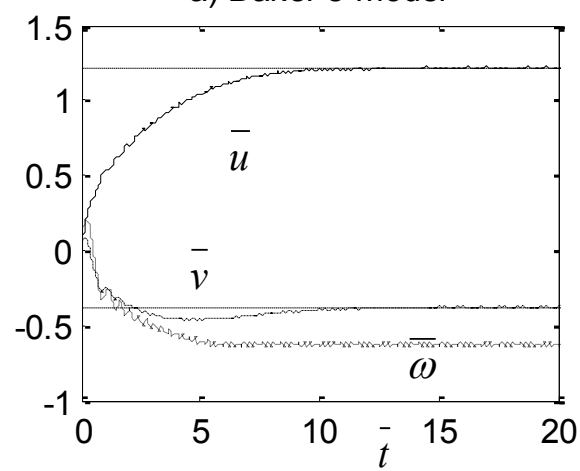

b) Holmes' model

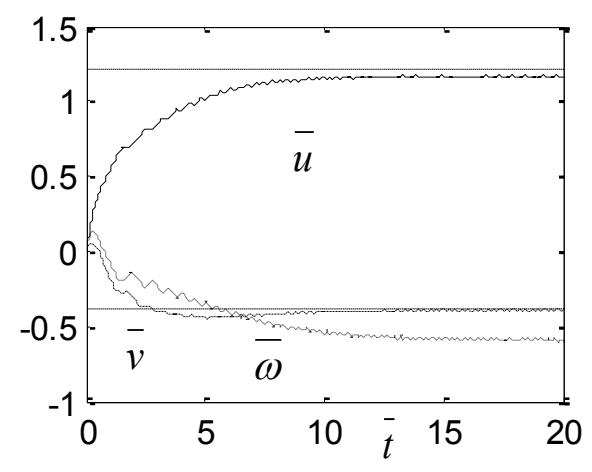

Orbit, Holmes

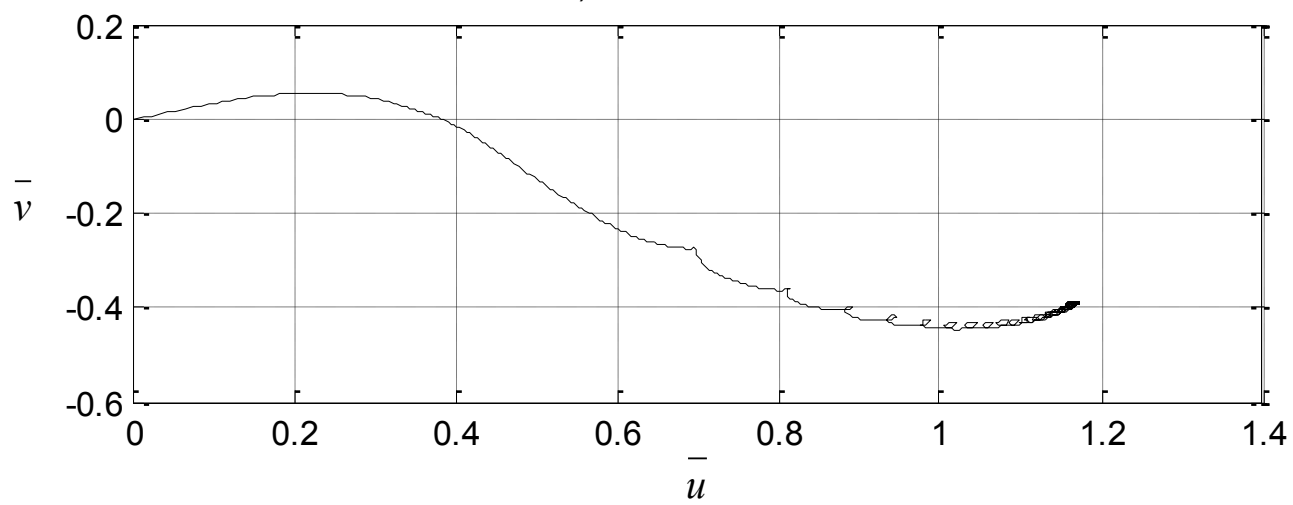

Figure 7: Large debris, negative final rotation. a) $\bar{u}, \bar{v}$ and $\bar{\omega}$ evolution, Baker's model,

b) $\bar{u}, \bar{v}$ and $\bar{\omega}$ evolution, Holmes' model. Dashed lines: asymptotic values of $\bar{u}$ and $\bar{v}$ from eq. (16) c) Projection of the system orbit in the $\bar{u}-\bar{v}$ plane.

The vertical velocity increases in modulus until $\bar{u}=1$. For larger $\bar{v}$ this sense of rotation produces positive lift forces and the final value of $\bar{v}$ becomes smaller. Holmes' model predicts in this case a smaller value of the kinetic energy than eq. (18). 
a ) kinetic energy, Baker

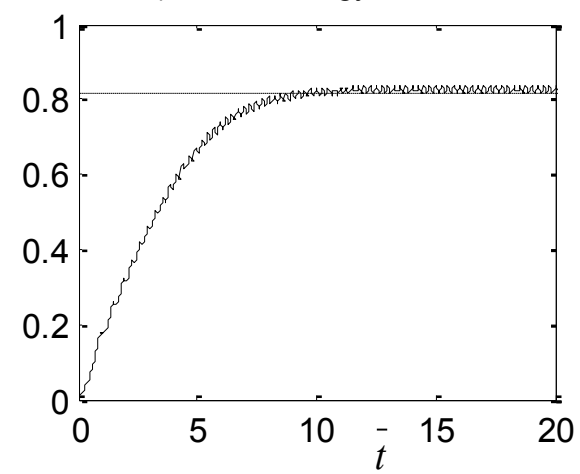

b ) kinetic energy, Holmes

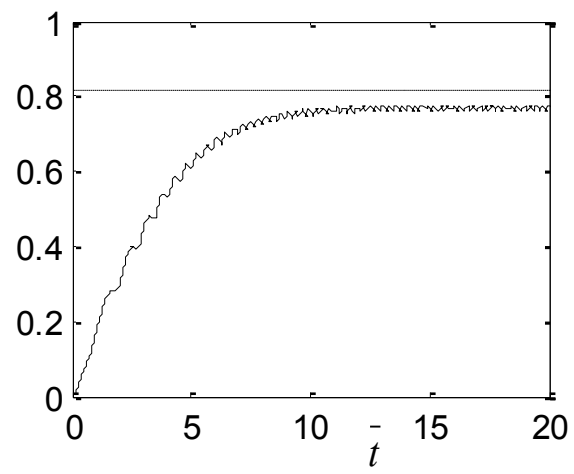

Orbit, Holmes

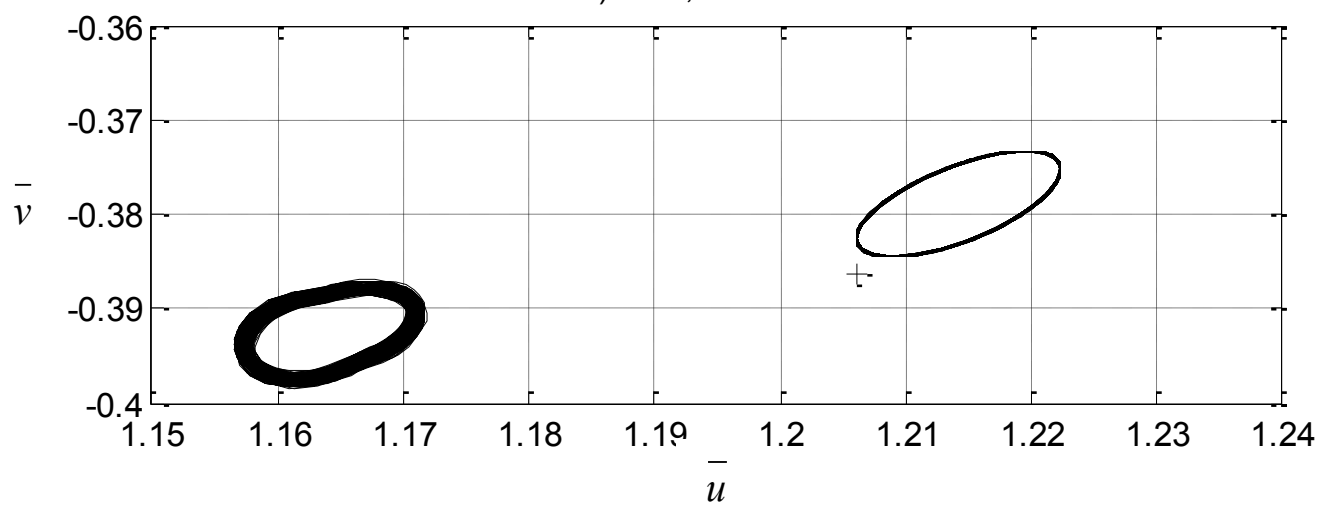

Figure 8: a) Kinetic energy evolution. Dashed: asymptotic value after eq. (17) b) Final orbits in $\bar{u}-\bar{v}$ space. The cross indicates the asymptotic final state

4.2.3 Small, heavy debris, $\left(\Omega=5, \Phi=0.03, \beta^{0}=15^{\circ}\right)$.

For increasing values of $\Omega$, which can imply either smaller debris or a lower wind velocity, a new final state appears, in which the vertical velocity $\bar{v}$ is larger than $\bar{u}$, and so we describe the sheet motion as "fall" rather than "flight", resembling that of a falling plate in the absence of wind.

Notable differences appear between the results of Baker's and Holmes' models in this case, as shown in Fig. (9) 
a) Baker 's model
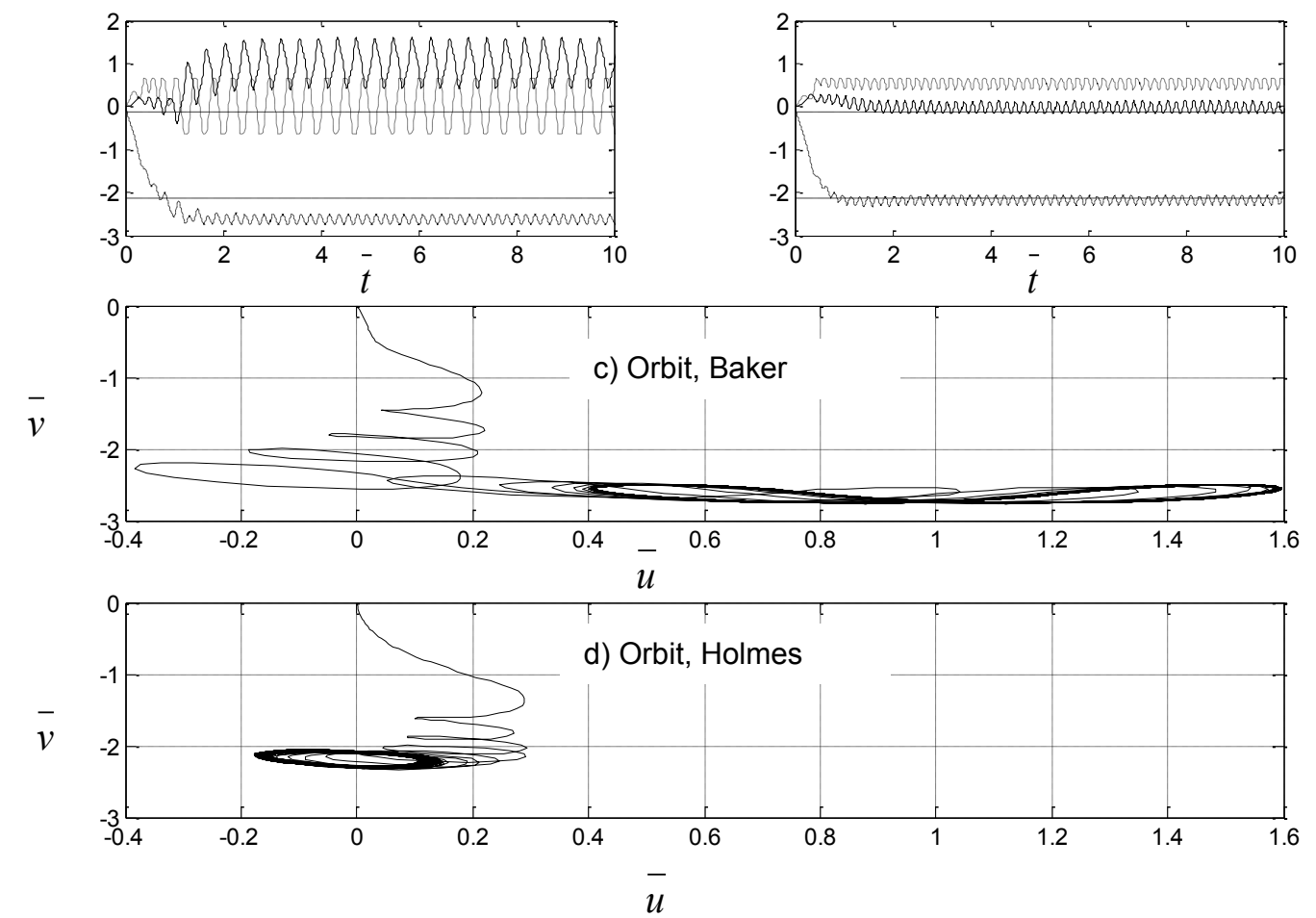

Figure 9: "Heavy debris": $\Phi=0.03, \Omega=5, \beta^{0}=15$. a) and b) Velocity evolution. c) and d) Final orbits in $\bar{u}-\bar{v}$ space.

For $\Omega=5, \Phi=0.03, \beta^{0}=15$, Holmes' model predicts fall with positive autorotation, only slightly influenced by the wind velocity. Baker's model, on the other hand, shows a falling motion with back and forth oscillations, not completing a roll. Nevertheless, this behaviour is reached at a non-dimensional time of 1 , which can represent $4.2 \mathrm{~s}$ of flight for a glass panel of $1.2 \mathrm{~m} \times 0.55 \mathrm{~m} \times 0.01 \mathrm{~m}$, falling in a low velocity building wake, with a local wind speed of $9 \mathrm{~m} / \mathrm{s}$. The panel will travel $15 \mathrm{~m}$, falling $55 \mathrm{~m}$.

It is interesting to note that these types of motions can be easily produced by letting fall strips of paper of different width/length ratio. In the absence of wind, this motion will reproduce the limit case for $\Omega \rightarrow \infty$. 
a ) kinetic energy, Baker

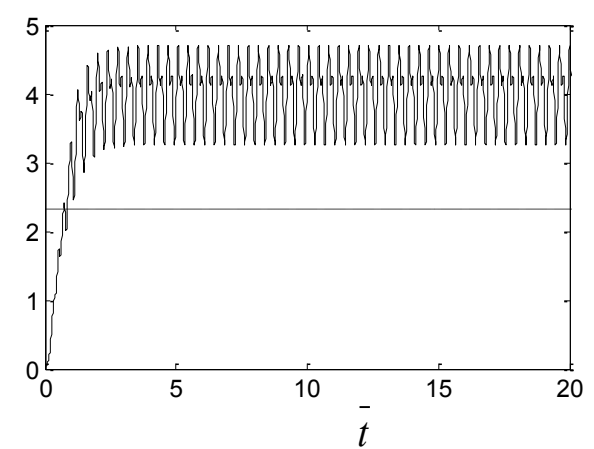

b) kinetic energy, Holmes

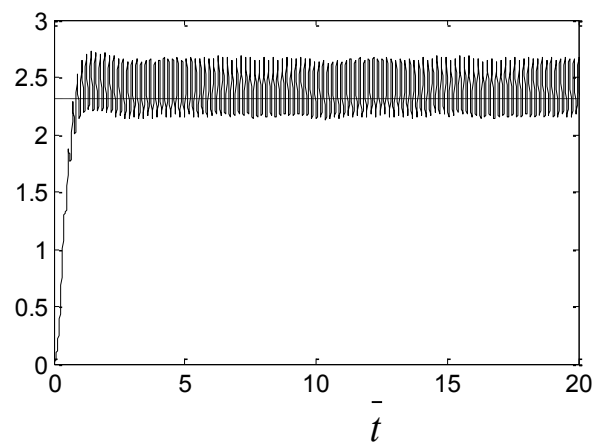

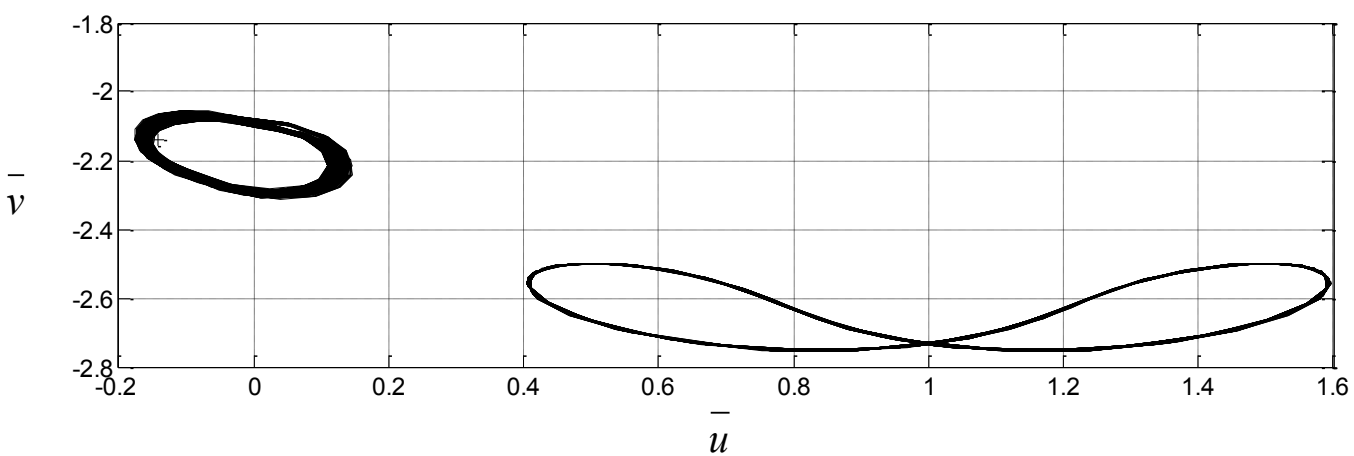

Figure 10: a) and b) Kinetic Energy with Baker's and Holmes' Model respectively. c) Final orbits with steady velocity values, $\Omega=5$.

The final orbits reached and their kinetic energy are shown in figure 10-c). While eq. (18) still gives a good estimate for Holmes' final orbit, Baker's model final state has instantaneous values higher than twice that asymptotic value.

The transition from a rotational regime to the back and forth oscillations was studied by varying the parameters $\Omega, \Phi$ and $\beta^{0}$ and results showed remarkable differences depending on the model used. In figure 11 , the sudden jumps in the quotient maximal / asymptotic kinetic energy mark the transition from one regime to a different one. For an initial incidence angle of $60^{\circ}$ and certain values of $\Omega$, the final state changes from negative to positive rotation, a transition indicated by the sudden fall in the final energy. 

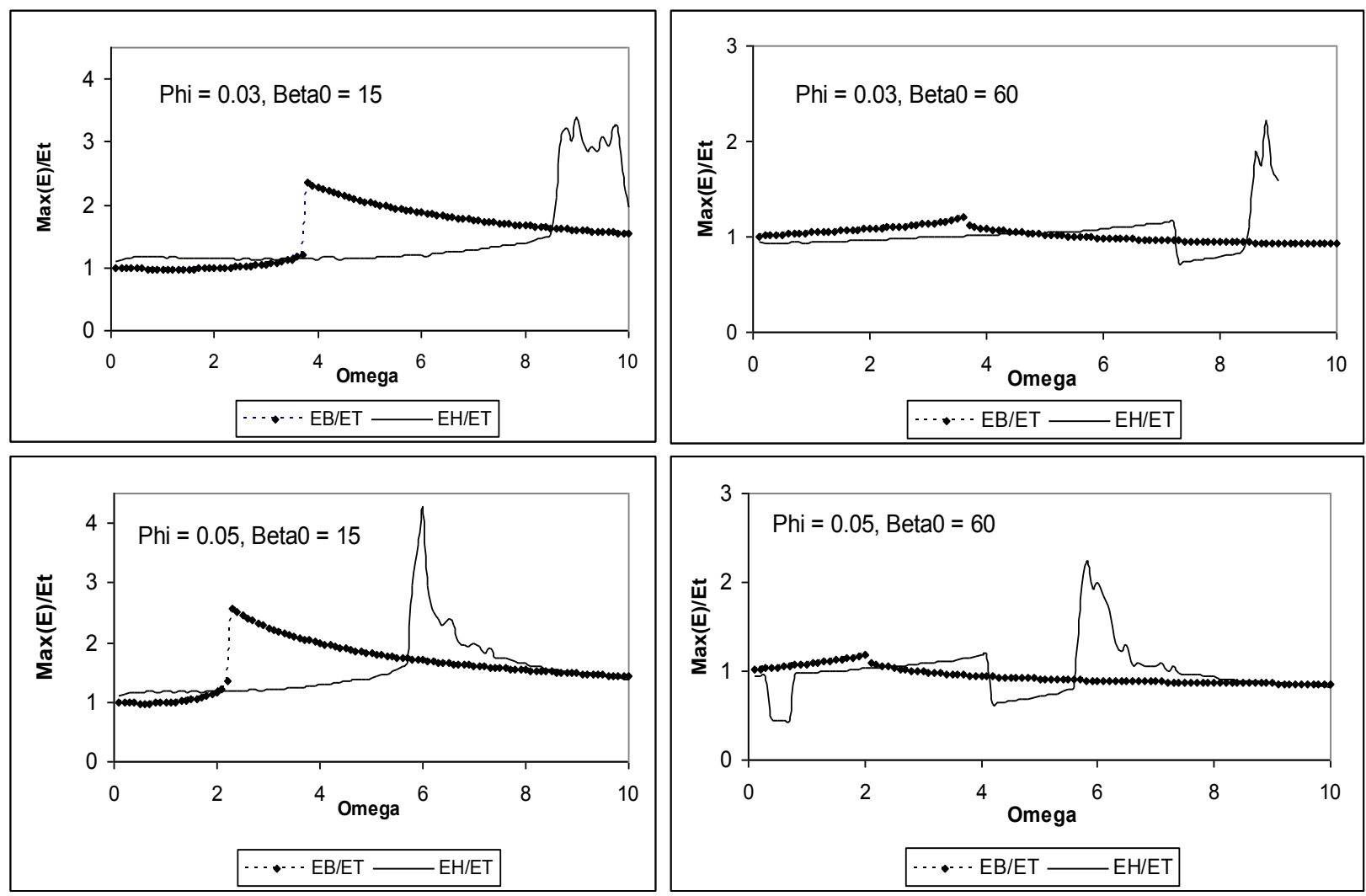

Figure 11: (Maximal kinetic energy)/(Asymptotic kinetic energy) vs. $\Omega$ for different values of $\Phi$ y $\beta^{\circ}$. EB: Baker's model, EH: Holmes' model.

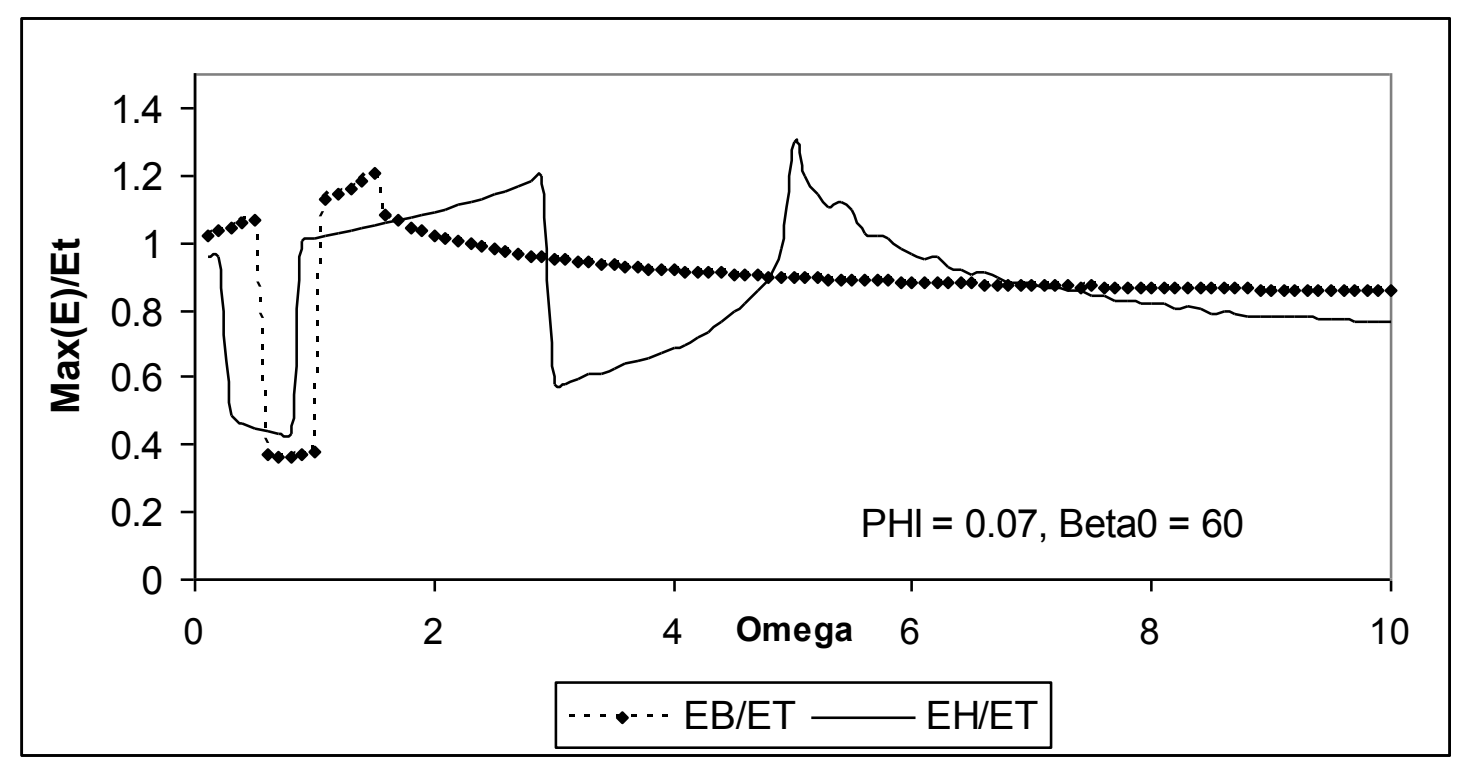

Figure 12: (Maximal kinetic energy)/(Asymptotic kinetic energy) vs. $\Omega$ for $\Phi=0.07$ y $\beta^{0}=60^{\circ}$.

It can be seen in figure 12 that the change in the final rotation sense is predicted, although with some difference in the values of $\Omega$, by both models for $\Phi=0.07$ and $\Omega$ between 0.3 and 
1. For larger $\Omega$, Holmes' model predicts a second change in the final rotation sense at $\Omega=$ 2.8, and transition to the oscillatory regime at $\Omega=5$, while Baker's model predicts this transition at the much lower value of 1.8 .

\section{CONCLUSIONS}

A dynamic analysis was carried out on the equations for the flight of sheet debris. Two different empirical models were used for the computation of aerodynamic coefficients and the results were compared.

The stability of the system initially at rest was analysed, finding that the characteristic polynomial of the linearised matrix has always positive eigenvalues, thus the system is always unstable and motion will start for any initial angle of attack, independently of the mass parameters $\Omega$ and $\Phi$.

After some oscillations the velocities $\bar{u}, \bar{v}$ and $\bar{\omega}$ of the sheet reach a final orbit. Depending on the parameters $\Omega=1 / T a$ and $\Phi=(0.5 \rho A l) / M$, two distinct final regimes appear: "sheet flight", with either positive or negative rotation, when the final horizontal velocity is larger than the vertical component, and "sheet fall" in the opposite case. In the latter one the sheet can fall rolling or with a back-and-forth oscillating motion, two possibilities than can be easily observed for a strip of paper in the absence of wind. The instantaneous kinetic energy in this condition can be as high as four times the value predicted from the equations of motion under the assumption of a final state of uniform angular velocity. Since during storms in cities debris are carried into building wakes and regions of local low wind velocity, the parameter $\Omega$ can increase and the motion change to a regime of higher kinetic energy than that predicted by a quasi-stationary rotation. The values of $\Omega$ and $\Phi$ that change the regime from "flying" to "falling" and the transition from "rotation" to "oscillation" have been found to depend strongly on the choice of the aerodynamic model. Both Baker's approximation for the aerodynamic coefficients with continuous trigonometric functions of the angle of attack 
and Holmes' fit of Hoerner's reports have proven to be good for predicting short time trajectories and for low values of $\Omega$ and $\Phi$, but for long times Baker's results diverge from those obtained with Holmes' model, not only quantitatively, but qualitatively, leading to very different final flight regimes. Experiments must be carried out in order to determine better models for the prediction of the long-time behaviour of sheet debris carried by the wind.

The numerical results state that the final orbit kinetic energy in case of oscillating fall is much larger than that predicted considering a hypothetical stationary state for $u, v$ and $\omega$, but this supposition does approximate reasonably the behaviour of plates when they rotate in a definite sense. For safe estimates of debris impact, both cases must be considered.

A word of caution is needed about the aerodynamic models employed, which are based in quasi-static force and moment measurements (Flachsbart, 1932) and at a fixed-point rotation. The non-stationary aerodynamic forces on rotating and oscillating plates can be very different than the quasi-static loads, with higher peaks and hysteresis cycles, as in the known effects of dynamic stall (Carr, 1988). since different models can lead to very different results, this work pretends to alert, on one side, for the possible wrong estimations of impact damage using simple models, and, on the other, for the need of better non-stationary force models for predictions of the flying sheet dynamics, range and impact damage.

Thus, the long term numerical results obtained in this work pretend simply to highlight the qualitative aspects of the sheet debris flight and to give a reasonable estimation of the debris impact energy, more than to give an accurate prediction of sheet debris trajectories and energy, which are also influenced by the wind shear, turbulence, and lateral forces not considered in this analysis. More wind tunnel experiments and full scale observations are needed in order to have better predictive tools for assessing the risk of debris impact.

\section{ACKNOWLEDGEMENTS}

This work was originated in two courses: "Wind effects in urban environments", by Prof. Chris Baker, in the University of La República Oriental del Uruguay, and "Introduction to Dynamical Systems and Chaos", by Prof. Alejandro Mesón and Manuel Carlevaro, 
University of La Plata, Argentina. The authors are grateful to Professors Baker, Mesón and Carlevaro for their suggestions and discussions on the topics here presented.

\section{REFERENCES}

Baker, C. J., (2007), "The debris flight equations", J. of Wind Eng. and Ind. Aerodynamics, 95 (5), 329-353.

Carr, L.W. 1988, Progress in analysis and prediction of dynamic stall, .J of Aircraft, 25 No. 1, pp 6-17.

Elsgoltz, L., (1977), "Teoría de la Estabilidad, Ecuaciones Diferenciales y Cálculo Variacional", 2nd ed., MIR, Moscow, pp. 207-219.

Flachsbart, O (1932), "Messungen an ebenen und gewolbten Platten", Ergebnisse der Aerodynamischen Versuchanstalt zu Goettingen,. IV.

Fremaux, C. M., Vairo, D. M., Whippe, R. D. (1995),"Effect of geometry and mass distribution on tumbling characteristics of flying wings" Journal of Aircraft 32 - 2, 404-410.

Gallaway, C. R.; Hankey, W. L. (1985) "Free-falling autorotating plate - A coupled fluid and flight mechanics problem". Journal of Aircraft 22 -11, 983-987.

Grassberger, P. and Procaccia, I. (1983). "Measuring the Strangeness of Strange Attractors". Physica D: Nonlinear Phenomena 9 (1-2): 189-208.

Hoerner, S. F.(1965) "Fluid-dynamic drag”. Hoerner Fluid Dynamics.

Holmes, J.D. (2004), "Trajectories of spheres in strong winds with applications to windborne debris". J. of Wind Eng. and Ind. Aerodynamics, 92, 9-22 
Holmes, J. D., Letchford, C.W. and Lin, N. (2006), "Investigations of plate-type windborne debris _ Part II: Computed trajectories". J. of Wind Eng. and Ind. Aerodynamics, 94, 21-39

Holmes, J.D., Baker, C. and Tamura, Y. (2006), "Tachikawa number: A proposal". J. of Wind Eng. and Ind. Aerodynamics 94, 41-47

Iversen, J. D. (1979), "Autorotating flat-plate wings: the effect of the moment of inertia, geometry and Reynolds number". J. of Fluid Mech. 92: 327-48

Lin, N., Letchford, C., Holmes, J.D. (2006), "Investigations on plat-type windborne debris, Part I, Experiments in full scale and wind tunnel", J. of Wind Eng. and Ind. Aerodynamics, 94 (2), 51-76.

Lugt, H.: “Autorotation”,Ann. Rev. Fluid Mech. 1983. 15:123-47

Mittal R., Seshadri, V, and Udaykumar, H., S., "Flutter, Tumble and Vortex Induced Autorotation", Theoretical and Computational Fluid Dynamics, Jan 2004: Published Online (DOI) $10.1007 / \mathrm{s} 00162-003-0101-5$

Tachikawa, M. (1983), "Trajectories of flat plates in uniform flow with applications to windgenerated missiles". J. of Wind Eng. and Ind. Aerodynamics 14, 443-453

Tachikawa, M. (1988), "A method for estimating the distribution range of trajectories of windborne missiles". J. of Wind Eng. and Ind. Aerodynamics 28, 175-184.

Wang, K., Letchford, C., "Flying debris behaviour", $11^{\text {th }}$ International Conference on Wind Engineering, Lubbock, TX, USA June 2-5 2003. 
Wills, J. A. B., Lee, B. E., Wyatt, T. A., (2002), "A model for wind-borne debris damage". J.

Wind. Eng. Ind. Aerodyn. 90, 555-565 